\title{
Socio-demographic determinants of full antenatal care services utilization among pregnant women delivering at a tertiary care hospital in Haryana
}

\author{
Vashisht B. ${ }^{1}$, Bhardwaj H. ${ }^{2 *}$, Chauhan M. ${ }^{3}$, Anvesha. ${ }^{4}$, Jaiprakash. ${ }^{5}$ \\ DOI: https://doi.org/10.17511/ijphr.2019.i4.02
}

${ }^{1}$ B.M. Vashisht, Professor, Department of Community Medicine, Pt. B.D. Sharma University Health Sciences, Rohtak, Haryana, India.

2* Himanshu Bhardwaj, Junior residents, Department of Community Medicine, Pt. B.D. Sharma University Health Sciences, Rohtak, Haryana, India.

3 Meenakshi Chauhan, Professor, Department of Obstetric and Gynaecology, Pt. B.D. Sharma University Health Sciences, Rohtak, Haryana, India.

${ }^{4}$ Anvesha, Junior Residents, Pt. B.D. Sharma University Health Sciences, Rohtak, Haryana, India.

5 Jaiprakash, Junior Residents, Pt. B.D. Sharma University Health Sciences, Rohtak, Haryana, India.

Introduction: In India, every year 28 million pregnancies take place of which 67,000 die due to maternal causes and one million women are left with chronic illnesses. Antenatal care is an important determinant of maternal and perinatal mortality. In India, full antenatal care utilization is only $21 \%$ (NFHS-4), which is far below the satisfactory level. Aim \& Objectives: To find out the socio-demographic factors affecting the utilization of full antenatal care services among recently delivered women. Material \& Methods: A cross-sectional study was carried out from Feb 2017- Feb 2018 among 500 pregnant females who recently delivered at PGIMS Rohtak. Results: Out of 500 subjects $-70.4 \%$ belonged to rural areas, $97.4 \%$ were Hindus, $81.4 \%$ were literate, $77.2 \%$ were unemployed $\&$ only $26.4 \%$ belonged to below poverty line. Majority $(97 \%)$ of participants underwent ANC checkup, $75 \%$ got themselves registered in first trimester, $92.2 \%$ of study subjects received 2 doses of $\pi$ / booster. $49.9 \%$ of study subjects had $4-7$ ANC visits, $38.2 \%$ of study subjects consumed more than 100 IFA tablets. Conclusion: Women and their family members need to be educated about the utilization of ANC services and their role in pregnancy.

Keywords: Antenatal care (ANC), Service utilization, Pregnant, Socio-demographic

Corresponding Author

Himanshu Bhardwaj, Junior residents, Department of Community Medicine, Pt. B.D. Sharma University Health Sciences, Rohtak, Haryana, India. Email: drhimanshubhardwaj1985@gmail.com
How to Cite this Article

Vashisht BM, Bhardwaj H, Chauhan M, Anvesha, Jaiprakash. Socio-demographic determinants of full antenatal care services utilization among pregnant women delivering at a tertiary care hospital in Haryana. Public Health Rev Int J Public Health Res. 2019;6(4):139-146.

Available From

https://publichealth.medresearch.in/index.php/ijphr/ article/view/112
To Browse

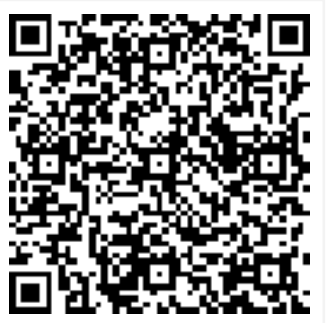




\section{Introduction}

In India, every year 28 million pregnancies take place of which 67,000 die due to maternal causes, one million women are left with chronic illnesses with one million neonatal deaths [1]. Maternal mortality ratio in India declined to 167 per lakh live births and neonatal mortality rate to 29 per thousand live births during 2015 [2, 3].

Antenatal period is a stressful period for both mother and foetus. The outcome of pregnancy is highly dependent on the antenatal care received by the pregnant woman. Hence, a good care of women during pregnancy is important to achieve a healthy mother and healthy baby at the end of pregnancy.

Antenatal care is an important determinant of maternal and perinatal mortality and is an essential component of maternal health care on which the health of mother and newborn depends [4].

Antenatal care in simple terms refers to the care that is given to an expectant mother from the confirmation of conception to the beginning of labour [5]. ANC is a type of preventive care with the goal of providing regular check-ups that allows health care providers for early identification, treatment and prevention of potential health problems throughout the course of pregnancy.

Moreover, ANC visits may raise awareness about the need for care during delivery and give women and their families a familiarity with the health facilities so that in emergency they can seek help more efficiently.

Regular ANC visits provide health personnel an opportunity to manage the pregnancy. It is a period during which a variety of services such as treatment of pregnancy induced hypertension (PIH), TT Immunization $[5,6]$, prophylaxis \& micronutrient supplementation are provided $[4,7,8]$.

ANC attendance among pregnant adolescents is particularly important as complications during pregnancy and childbirth have been shown to be a major cause of death among girls aged 15-19 years in low- and middle-income countries [9].

One of the major factors contributing to high rate of adverse birth outcome is slow improvement in prenatal \& maternal health services [10]. ANC remains one of the safe motherhood interventions which if properly implemented has the potential to significantly reduce maternal \& perinatal mortality 「11].
The antenatal period provides opportunities for reaching pregnant women for interventions to improve maternal \& neonatal health [5-9].

For effective antenatal care- early registration, at least 4 antenatal check-ups, administration of 2 doses of $\pi$ injection and at least 100 tablets of iron $\&$ folic acid should be ensured.

In India, full antenatal care utilization is only $21 \%$ and in Haryana it is only $19 \%$ (NFHS -4 ), which is far below the satisfactory level. So the current study was planned to study the socio-demograhic determinants responsible for full ANC utilization.

\section{Material \& Methods}

A Cross-Sectional hospital based observational study was carried out among pregnant women who delivered at Pt. B D Sharma PGIMS, Rohtak, Haryana in the department of Obstetrics \& Gynaecology. The study was conducted over a period of one year from Apr 2017 to Apr 2018.

Sample size: According to NFHS-4 data for Haryana, $45.1 \%$ mothers reported for at least 4 antenatal care visits. Hence, taking the prevalence as $45.1 \%$, confidence interval $95 \%$ and allowable error of $15 \%$, sample size was calculated using the formula

$(Z 1-a / 2) 2 \times p \times q$

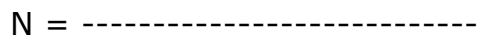

D2

Where,

$Z=$ standard normal variate

$\mathrm{Z} 1-\mathrm{a} / 2$ = value of two tailed alpha error; this is 1.96 at $5 \%$

$\mathrm{P}=$ expected prevalence in fraction

$\mathrm{Q}=1-\mathrm{p}$

$D=$ allowable error (taken as $15 \%$ )

Sample size came out to be 467 . Assuming a nonresponse rate of $5 \%$, it was planned to include 500 participants in the study and 500 subjects were interviewed.

Sampling technique: As per the data available from the department of Obstetrics and Gynaecology, 30-40 deliveries per day are conducted in PGIMS, Rohtak. So, on each day of visit, a list of women who delivered on the previous day was prepared 
From the labour room register.

From this list, 8-10 delivered women were selected using simple random sampling technique using lottery method.

Consent: Each study participant was explained about the study and an informed written consent in vernacular language was taken from each of them before the conduct of the study. The confidentiality of the collected data was assured.

\section{Inclusion criteria}

01. Women who delivered at PGIMS Rohtak.

02. Women who delivered after completion of 28 weeks of gestation, irrespective of the outcome.

03. Stillbirths were also included in the study.

\section{Exclusion criteria}

01. Women who did not give the consent for the study.

02. Women who left against medical advice (LAMA) after delivery.

03. Women who had psychiatric illness and were severely ill.

Methodology: On the day of visit, 8-10 delivered women were selected using simple random sampling and the selected women were briefed about the nature and purpose of the study and interviewed one by one after taking their consent.

A pre-designed, pre- tested, semi-structured interview schedule, which consisted of questions regarding their socio-demographic profile, obstetric history and medical history was used for recoding their response.

The details about the utilization of antenatal care services by the subjects was also enquired which included booked or unbooked ANC check-ups, period of gestation at first ANC, place and person who conducted ANC, number of ANC visits, examination $\&$ investigations etc. done if any. Information was also recorded regarding $\Pi \mathrm{T}$ immunization, number of IFA tablets consumed.

History of present labour was also enquired in detail which included date, time \& mode of delivery. Confidentiality of the information was maintained. For socio-economic status of the subjects, revised B.G. Prasad Scale for the Year 2017 was used.

Data analysis: Collected data were compiled, coded appropriately and entered in the MS EXCEL spread sheet and were cleaned for any possible
Typographical error. Analysis was carried out using SPSS vs 20.0 (Statistical Package for Social Sciences) and appropriate statistical tests were applied wherever applicable.

\section{Operational Definitions}

\section{ANC Registration}

Booked: All mothers who were registered for antenatal check-up and having tracking ID and ANC card issued by health providers.

Full antenatal care- considered as a proxy of quality antenatal care. It has three components which are as follows:

01. a) ANC visits -at least four times.

02. b) IFA- tablets - at least 100 tablets to be consumed.

03. c) TT Immunization -2 Doses of $\pi$ Injection at one month apart or a single booster dose if the pregnancy interval was less than three years and in the last pregnancy both the doses were received.

\section{Results}

Table-1: Distribution of Study Subjects
according to their Socio-Demographic
Characteristics $(n=500)$

\begin{tabular}{|c|l|l|l|}
\hline Variable & \multicolumn{1}{|c|}{ Category } & Frequency & Percentage \\
\hline \multirow{4}{*}{ Age in years } & $18-21$ & 111 & 22.2 \\
\cline { 2 - 4 } & $22-25$ & 254 & 50.8 \\
\cline { 2 - 4 } & $26-29$ & 66 & 13.2 \\
\cline { 2 - 4 } & $>30$ & 69 & 13.8 \\
\hline \multirow{5}{*}{ Area of residence } & Urban & 148 & 29.6 \\
\cline { 2 - 4 } & Rural & 352 & 70.4 \\
\hline \multirow{5}{*}{ Caste } & Hindu & 487 & 97.4 \\
\cline { 2 - 4 } & Muslim & 7 & 1.4 \\
\cline { 2 - 4 } & Christian & 1 & 0.2 \\
\cline { 2 - 4 } & Sikh & 5 & 1 \\
\hline & General & 149 & 29.8 \\
\cline { 2 - 4 } & OBC & 157 & 31.4 \\
\cline { 2 - 4 } & SC & 188 & 37.6 \\
\cline { 2 - 4 } & ST & 6 & 1.2 \\
\hline \multirow{5}{*}{ Family type } & Joint & 281 & 56.2 \\
\cline { 2 - 4 } & Nuclear & 219 & 43.8 \\
\hline
\end{tabular}

Out of 500 study subjects, majority $(50.8 \%)$ belonged to the age group 22 to 25 years, followed by 18 to 21 years $(22.2 \%)$, more than 30 years $(13.8 \%)$ and 26 to 29 years (13.2\%). Majority (70.4\%) of study population resided in urban and while $29.6 \%$ in rural areas. 
Majority $(97.4 \%)$ of subjects were Hindus followed by Muslims (1.4\%), Sikhs (1\%) and Christians $(0.2 \%)$. Majority $(37.6 \%)$ of study subjects belonged to SC category followed by OBC (31.4\%), General $(29.8 \%)$ and ST (1.2\%). Majority (56.2\%) of study subjects belonged to joint family.

Table-2: Distribution of Study Subjects according to their Socio-economic characteristics $(n=500)$

\begin{tabular}{|c|l|l|l|}
\hline Variable & \multicolumn{1}{|c|}{ Category } & Frequency & Percentage \\
\hline \multirow{5}{*}{ Education } & Illiterate & 93 & 18.6 \\
\cline { 2 - 4 } & Primary school & 17 & 3.4 \\
\cline { 2 - 4 } & Middle school & 120 & 24 \\
\cline { 2 - 4 } & Secondary school level & 178 & 35.6 \\
\cline { 2 - 4 } & Graduate and above & 92 & 18.4 \\
\hline \multirow{5}{*}{ Occupation } & Unemployed & 436 & 87.2 \\
\cline { 2 - 4 } & Unskilled & 37 & 7.4 \\
\cline { 2 - 4 } & Semiskilled & 8 & 1.6 \\
\cline { 2 - 4 } & Skilled & 9 & 1.8 \\
\cline { 2 - 4 } & Semi professional & 9 & 1.8 \\
\cline { 2 - 4 } & Professional & 1 & 0.2 \\
\hline BPL card holder & Yes & 132 & 26.4 \\
\cline { 2 - 4 } & No & 368 & 73.4 \\
\hline \multirow{5}{*}{ Socioeconomic class } & III & 14 & 2.8 \\
\cline { 2 - 4 } & IV & 174 & 34.8 \\
\hline & II & 160 & 32 \\
\cline { 2 - 4 } & I & 37 & 23 \\
\hline
\end{tabular}

Majority $(35.6 \%)$ of study subjects were educated up to secondary level followed by middle $(24 \%)$, illiterate $(18.6 \%)$, graduate and above $(18.4 \%)$ and primary $(3.4 \%)$. Majority $(87.2 \%)$ of study subjects were unemployed followed by unskilled workers $(7.4 \%)$, skilled \& semi-professionals ( $1.8 \%$ each), semi-skilled $(1.6 \%)$ and professionals $(0.2 \%)$.

Majority $(34.8 \%)$ of study subjects belonged to class IV followed by class III (32\%), class II (23\%), class I $(7.4 \%)$ and only $2.8 \%$ belonged to class V. Majority $(73.6 \%)$ of study population did not have below poverty line (BPL) card while $26.4 \%$ had BPL card.

Table-3: Distribution of study subjects according to number of ANC visits $(n=485)$

\begin{tabular}{|l|l|l|}
\hline \multicolumn{1}{|c|}{ ANC visits } & \multicolumn{1}{c|}{ Frequency } & \multicolumn{1}{c|}{ Percentage } \\
\hline $1-3$ & 185 & 38.1 \\
\hline $4-7$ & 242 & 49.9 \\
\hline $8-12$ & 44 & 9.1 \\
\hline$>13$ & 14 & 2.9 \\
\hline Total & 485 & 100 \\
\hline
\end{tabular}

Out of total 500 participants, $3 \%$ (15) of the participants did not undergo ANC utilization even once.

Table 3 shows that majority $(49.9 \%)$ of study who underwent ANC checkups had 4-7 ANC visits followed by $1-3$ (38.1\%) and 8-12 ANC visits (9.1\%). Only $2.9 \%$ females had more than 13 ANC visits.

Table-4: Distribution of study subjects according to TT immunization $(n=500)$

\begin{tabular}{|l|l|l|}
\hline \multicolumn{1}{|c|}{ TT } & \multicolumn{1}{c|}{ Prequency } & \multicolumn{1}{c|}{ Percentage } \\
\hline$\pi 1$ & 13 & 2.6 \\
\hline$\pi 2 /$ Booster & 461 & 92.2 \\
\hline Not received & 26 & 5.2 \\
\hline Total & 500 & 100.0 \\
\hline
\end{tabular}

Table 4 shows that majority $(92.2 \%)$ of study subjects received 2 doses of $\pi /$ booster. $2.6 \%$ females received only one dose of $\Pi$, whereas, $5.2 \%$ females did not receive any dose of $\pi$.

Table-5: Distribution of study subjects according to consumption of IFA tablets $(n=500)$

\begin{tabular}{|l|l|l|}
\hline \multicolumn{1}{|c|}{ IFA tablets } & \multicolumn{1}{c|}{ Frequency } & \multicolumn{1}{c|}{ Percentage } \\
\hline None & 105 & 21.0 \\
\hline$<50$ & 99 & 19.8 \\
\hline $50-100$ & 105 & 21.0 \\
\hline$>100$ & 191 & 38.2 \\
\hline Total & 500 & 100.0 \\
\hline
\end{tabular}

Table 5 shows that majority (38.2\%) of study subjects consumed more than 100 IFA tablets.

$21 \%$ females consumed $50-100$ tablets and $19.8 \%$ females consumed less than 50 tablets. $21 \%$ females did not consumed any IFA tablet.

Table-6: Distribution of study subjects according to full ANC utilization $(n=500)$

\begin{tabular}{|l|l|l|}
\hline \multicolumn{1}{|c|}{ Full ANC } & \multicolumn{1}{|c|}{ Frequency } & \multicolumn{1}{c|}{ Percentage } \\
\hline Yes & 195 & 39 \\
\hline No & 305 & 61 \\
\hline Total & 500 & 100 \\
\hline
\end{tabular}

Table 6 shows that majority $(61 \%)$ of study subjects did not receive full ANC.

One or the other component of full ANC (minimum 4 ANCs, 2 doses of $T$ T and consumption of 100 IFA tablets) was missing.

Only $39 \%$ females received full ante natal care. 
Table-7: Full antenatal care (ANC) and its association with profile of study subjects $(n=500)$

\begin{tabular}{|c|c|c|c|c|c|}
\hline \multirow[t]{2}{*}{ Variable } & \multirow[t]{2}{*}{ Category } & \multicolumn{2}{|c|}{$\begin{array}{l}\text { Full ANC (No. } \\
\qquad \% \text { ) }\end{array}$} & \multirow[t]{2}{*}{ Total } & \multirow[t]{2}{*}{ Test value } \\
\hline & & Yes & No & & \\
\hline \multirow[t]{4}{*}{ Age in years } & $18-21$ & $40(36)$ & $71(64)$ & 111 & \multirow[t]{4}{*}{$x 2=3.422$} \\
\hline & $22-25$ & $99(39)$ & $155(61)$ & 254 & \\
\hline & $26-29$ & $\begin{array}{l}32(48 . \\
5)\end{array}$ & $34(51.5)$ & 66 & \\
\hline & $>30$ & $\begin{array}{l}24(34 . \\
8)\end{array}$ & $45(65.2)$ & 69 & \\
\hline \multirow[t]{3}{*}{ Caste } & General & 56(37. & $93(62.4)$ & 149 & \multirow{3}{*}{$\begin{array}{l}x 2=1.307 \\
p \text {-value- } \\
0.520\end{array}$} \\
\hline & OBC & $\begin{array}{l}67(42 . \\
7)\end{array}$ & $90(57.3)$ & 157 & \\
\hline & $\mathrm{SC} / \mathrm{ST}$ & $\begin{array}{l}72(37 . \\
1)\end{array}$ & $122(62.9)$ & 194 & \\
\hline \multirow[t]{5}{*}{ Education } & Illiterate & $\begin{array}{l}22(23 . \\
7)\end{array}$ & $71(76.3)$ & 93 & \multirow{5}{*}{$\begin{array}{l}x 2=14.308, \\
p \text {-value- } \\
0.006\end{array}$} \\
\hline & Primary school & $6(35.3$ & $11(64.7)$ & 17 & \\
\hline & Middle school & $\begin{array}{l}49(40 . \\
8)\end{array}$ & $71(59.2)$ & 120 & \\
\hline & Secondary level & $\begin{array}{l}72(40 . \\
4)\end{array}$ & $106(59.6)$ & 178 & \\
\hline & $\begin{array}{l}\text { Graduate and } \\
\text { above }\end{array}$ & $46(50)$ & $46(50)$ & 92 & \\
\hline \multirow[t]{6}{*}{ Occupation } & Unemployed & $\begin{array}{l}169(3 \\
8.8)\end{array}$ & $267(61.2)$ & 436 & \multirow{6}{*}{$\begin{array}{l}x 2=8.194 \\
p \text {-value- } \\
0.146\end{array}$} \\
\hline & Unskilled & $\begin{array}{l}11(29 . \\
7)\end{array}$ & $26(70.3)$ & 37 & \\
\hline & Semiskilled & $4(50)$ & $4(50)$ & 8 & \\
\hline & Skilled & $4(44.4$ & $5(55.6)$ & 9 & \\
\hline & Semi professional & $7(77.8$ & $2(22.2)$ & 9 & \\
\hline & Professional & 0 & $1(100)$ & 1 & \\
\hline \multirow[t]{2}{*}{ Family type } & Joint & $\begin{array}{l}111(3 \\
9.5)\end{array}$ & $\begin{array}{l}170(60.0 \\
5)\end{array}$ & 281 & \multirow{2}{*}{$\begin{array}{l}x 2=0.068 \\
p \text {-value- } \\
0.794\end{array}$} \\
\hline & Nuclear & $\begin{array}{l}84(38 . \\
4)\end{array}$ & $135(61.6)$ & 219 & \\
\hline \multirow[t]{5}{*}{$\begin{array}{l}\text { Socioeconomic } \\
\text { class }\end{array}$} & I & $4(28.6$ & $10(71.4)$ & 14 & \multirow{5}{*}{$\begin{array}{l}x 2=4.819 \\
p \text {-value- } \\
0.306\end{array}$} \\
\hline & II & $\begin{array}{l}58(33 . \\
3)\end{array}$ & $116(66.7)$ & 174 & \\
\hline & III & $\begin{array}{l}68(42 . \\
5)\end{array}$ & $92(57.5)$ & 160 & \\
\hline & IV & $\begin{array}{l}50(43 . \\
5)\end{array}$ & $65(56.5)$ & 115 & \\
\hline & V & $\begin{array}{l}15(40 . \\
5)\end{array}$ & $22(59.5)$ & 37 & \\
\hline
\end{tabular}

\begin{tabular}{|l|l|l|l|l|l|}
\hline Religion & Hindu & $190(30)$ & $297(61)$ & 487 & X2=1.886, \\
\cline { 2 - 5 } & Muslim & $2(28.6)$ & $5(71.4)$ & 7 & p-value-0.596 \\
\cline { 2 - 5 } & Christian & $1(100)$ & $0(0)$ & 1 & \\
\cline { 2 - 5 } & Sikh & $2(40)$ & $3(60)$ & 5 & \\
\hline
\end{tabular}

Table 7 shows the break-up of women who received full ANC and did not receive and their association with socio-demographic profile of study subjects.

Significant difference was observed in terms of education of study subjects. Out of 500 study subjects higher proportion of full ANC was observed among women with education up to graduate and above, middle school, Secondary school and primary school (50\%, 40.8\%, $40.4 \%$ and $35.3 \%$ respectively) as compared to illiterates (23.7\%) and the difference was statistically significant $(p<0.01)$.

The influence of age, caste, family type, socioeconomic status and religion was not statistically significant.

\section{Discussion}

In the present study it was found that the sociodemographic factor which is affecting full ANC utilization is education of the mother. Higher proportion of full ANC was observed among women with education up to graduate and above, middle school, Secondary school and primary school (50\%, $40.8 \%, 40.4 \%$ and $35.3 \%$ respectively) as compared to illiterates (23.7\%).

Similar findings were reported by Bhattacherjee et al (2013) [12] in their study from West Bengal. They did not found any significant association between full antenatal care utilization and the mothers' age, religion and caste, but similar to present study they found that literacy of the women (OR 2.21) had a positive relation with antenatal care utilization.

Similar finding was reported by Pandey et al (2014) [13] in their study, who reported that women with higher education were twice more likely to receive antenatal care than women with no education. Unlike the results of present study, they also reported that age, income, type of family were strongly associated with the attendance at antenatal care service.

Jahan et al (2016) [14] in their study also stated that women with higher education status were more likely to take adequate ANC. They found that women with no education, primary and secondary education had received adequate ANC 0.03, 0.06 and 0.14 times less than women with higher 
Education. So women with primary education were 94 percent less likely to receive adequate ANC than highly educated women. Adhikari et al (2016) [15] in their study also found that ANC utilization was highest among those women with level of education 9th class and above (15-28\%) which is also in concordance with the findings of present study.

Majority $(49.9 \%)$ of present study subjects had undergone 4-7ANC check-ups followed by $38.1 \%$ who had 1-3 ANC visits. 9.1\% females underwent 812 ANC visits and only $2.9 \%$ females had more than 13 ANC visits. Almost similar results were shown by Kakati $\mathrm{R}$ et al (2016) [16] who found that $68.7 \%$ women had more than three antenatal visits, whereas, Uppadhaya S et al (2017) [17] in their study found that only $32.8 \%$ mothers received four or more antenatal check-ups. Majority ( $81.8 \%$ ) of the present study subjects had received 2 doses of TT immunization followed by $10.4 \%$ females who had received booster.

So, $92.2 \%$ study subjects were protected against tetanus. $2.6 \%$ females took only one $\Pi T$ injection, whereas, $5.2 \%$ females did not take any dose of $\pi$. Similar, results were quoted by Kakati R et al (2016) [16] who showed that $90 \%$ of study subjects were immunized with TT. Sharma $N$ et al (2017) [18] also reported the similar results in which majority $(65.6 \%)$ of the subjects were fully immunized with 2 doses/booster of $\mathrm{TT}$.

Majority (38.2\%) of the present study subjects consumed more than 100 IFA tablets. $21 \%$ females consumed $50-100$ tablets and $19.8 \%$ females consumed less than 50 tablets. $21 \%$ females did not take any IFA tablet. Iyenagar $S$ et al (2009) [19] conducted a survey which showed that iron and folic acid (IFA) tablets reached $58 \%$ of women.

However, only $13 \%$ consumed IFA tablets for 90 days or more. Malik et al (2013) [20] conducted a similar study which showed that $97.4 \%$ received 100 tablets of IFA, however, less than half of them consumed all the tablets. Abdullahi $\mathrm{H}$ et al (2014) [21] conducted a study on antenatal iron and folic acid supplementation use by pregnant women in Khartoum Sudan.

They found that out of 856 women, $92.1 \%$ used iron-folic acid supplementation during pregnancy and $65.4 \%$ used folic acid. Majority (61\%) of present study subjects did not undergo full ANC check-ups. Only 39\% females received full ANC. Almost similar results were found by $\mathrm{Q} i$ Zhao et al (2012) [22] who showed that 49.7\% had
Adequately utilized antenatal care, 90.1\% females made at least one antenatal care visit, while only $19.7 \%$ of women visited an antenatal care center during the first trimester (12 weeks). Narayana Murthy MR et al (2016) [23] showed in their study that full ANC services were utilized by $93 \%$ women.

\section{Conclusion \& Recommendation}

In present study it is found that there is statistically significant difference in terms of education and utilization of full ANC, with increase in education level of females, ANC utilization was high.

Thus till the meantime education level of women in the community is improved, efforts to encourage women to attend ANC could be targeted at less educated women and it should include formal or informal education sessions for younger women on topics like ANC and childbirth. Within the limited resources, safe motherhood strategies need to be targeted in order to increase access to antenatal and delivery care.

Such interventions may include preparing community health workers to promote ANC using various IEC (information, education and communication) materials, improving the quality of ANC offered and strengthening health systems to ensure the availability of medical supplies.

\section{What the study adds to the existing knowledge}

In our country, the NFHS-4 and DLHS-4 surveys have shown that the utilization of antenatal care services is far from satisfactory. It has also been found that, utilization of ANC services in Haryana is low as compared to southern states, where the utilization is high. The present study was planned to find out its socio-demographic determinant and it was found that with increase in education level of females, full ANC utilization was high. The influence of other socio-demographic determinants like age, caste, family type, socio-economic status and religion was not statistically significant.

\section{Author's Contributions}

Dr. B. M Vashisht: The whole concept of the studyselecting topic, whole layout of the study, finalizing the methodology and final proof reading of the manuscript.

Dr. Himanshu Bhardwaj: reviewed all the 
Literature, collected, analyzed and interpreted the data for final results.

Dr. Meenakshi: Selections of the subjects from Obstetrics and Gynecology and guidance in manuscript writing.

Dr. Anvesha: Data collection, analysis of results, final manuscript writing and editing.

Dr Jai Prakash: Sorting the data

\section{Reference}

01. Government of India. Estimates of Mortality Indicators 2010. Office of the Registrar General (Government of India); Sample Registration System. 2010.

[Crossref]

02. Liu L, Oza S, Hogan D, Perin J, Rudan I, Lawn JE, et al. Global, regional, and national causes of child mortality in 2000-13, with projections to inform post-2015 priorities- an updated systematic analysis. Lancet. 2015;385(9966)430-440.

doi: 10.1016/S0140-6736 (14) 61698-6. Epub 2014 Sep 30 [Crossref]

03. Registrar General of India. Sample registration system (SRS) statistical report 2013. Office of Registrar general of India; New Delhi. 2013. [Crossref]

04. Ghosh-Jerath S, Devasenapathy N, Singh A, Shankar A, Zodpey S. Ante natal care (ANC) utilization, dietary practices and nutritional outcomes in pregnant and recently delivered women in urban slums of Delhi, India- an exploratory cross-sectional study. Reprod Health. $2015 ; 12 ; 20$.

doi: 10.1186/s12978-015-0008-9 [Crossref]

05. Simkhada B, Teijlingen ER, Porter M, Simkhada $P$. Factors affecting the utilization of antenatal care in developing countries: systematic review of the literature. J Adv Nurs. 2008;61(3)244260.

doi: $10.1111 / \mathrm{j} .1365-2648.2007 .04532 . x$ [Crossref]

06. Overbosch GB, Nsowah-Nuamah NN, Van den Boom GJ, Damnyag L. Determinants of antenatal care use in Ghana. J Africa Econom. 2004; 13(2)277-301.

[Crossref]
07. Raatikainen K, Heiskanen N, Heinonen S. Underattending free antenatal care is associated with adverse pregnancy outcomes. BMC Public Health. $2007 ; 7 ; 268$. doi:10.1186/1471-2458-7-268 [Crossref]

08. Magadi MA, Madise NJ, Rodrigues RN. Frequency and timing of antenatal care in Kenyaexplaining the variations between women of different communities. Soc Sci Med. $2000 ; 51(4) \backslash 551-561$.

doi:10.1016/s0277-9536 (99)00495-5 [Crossref]

09. Fotso JC, Ezeh AC, Essendi H. Maternal health in resource-poor urban settings- how does women's autonomy influence the utilization of obstetric care services?. Reprod Health. $2009 ; 6 ; 9$.

doi: $10.1186 / 1742-4755-6-9$ [Crossref]

10. Ghai OP, Gupta P. Essential Preventive MedicineA Clinical and Applied Orientation. Vikas Publishing House Pvt Ltd. 1999.

[Crossref]

11. Indian Council of Medical Research. A national collaborative study of identification of high-risk families, mothers and outcome of their offspring with particular references to the problem of maternal nutrition, low birth weight, perinatal and infant morbidity and mortality in rural urban slum countries. New Delhi. 1990.

[Crossref]

12. Bhattacherjee S, Datta S, Saha JB, Chakraborty M. Maternal health care services utilization in tea gardens of Darjeeling, India. J Bas Clinic Reprod Sci. $2013 ; 2(2) 77-84$. doi: $10.4103 / 2278-960 X .118645$ [Crossref]

13. Pandey S, Karki S. Socio-economic and Demographic Determinants of Antenatal Care Services Utilization in Central Nepal. Int J $\mathrm{MCH}$ AIDS. 2014;2(2)212-219.

[Crossref]

14. Jahan M, Jahan E. Socio-demographic determinants influencing antenatal care seeking behaviour among women in Bangladesh- an application of factor analysis. Int J Comm Med Pub Health. 2017;3(4)925-930.

doi: 10.18203/2394-6040.ijcmph20160930 [Crossref] 
15. Adhikari T, Sahu D, Nair S, Saha KB, Sharma RK, Pandey A. Factors associated with utilization of antenatal care services among tribal womenA study of selected States. Indian J Med Res. 2016;144(1)58-66.

doi: $10.4103 / 0971-5916.193284$ [Crossref]

16. Kakati R, Barua K, Borah M. Factors associated with the utilization of antenatal care services in rural areas of Assam, India. Int J Comm Med Pub Health. 2016;3(10)2799-2805.

doi: $\quad 10.18203 / 2394-6040 . i j \quad c m p h \quad 20163364$ [Crossref]

17. Uppadhaya SK, Agrawal N, Bhansali S, Garg K, Singh M. Utilization of antenatal health care services and its impact on birth weight of newborn in rural area of Western Rajasthan, India. Int $\mathrm{J}$ Comm Med Pub Health. 2017;4(3)680-685.

doi: 18203 /2394-6040.ijcmph20170739 [Article] [Crossref]

18. Sharma N, HV KK, Devgan S. A study on utilization of antenatal care services in urban slums of Amritsar city, Punjab, India. Int J Comm Med Pub Health. 2017;4(3)698-703.

doi: 18203/2394-6040.ijcmph20170742 [Article] [Crossref]

19. Iyengar SD, Iyengar K, Gupta V. Maternal health- a case study of Rajasthan. J Health Popul Nutr. 2009;27(2)271-292.

doi: $10.3329 /$ jhpn.v27i2.3369 [Crossref]
20. Malik JS, Kalhan M, Punia A, Sachdeva S, Behera BK. Utilization of health services under Janani Suraksha Yojna in rural Haryana. Int J Med Pub Health. 2013;3(3)176-179.

doi: 118977 [Article] [Crossref]

21. Abdullahi H, Gasim GI, Saeed A, Imam AM, Adam I. Antenatal iron and folic acid supplementation use by pregnant women in Khartoum, Sudan. BMC Res Notes. $2014 ; 7 ; 498$. doi: 10.1186/1756-0500-7-498 [Crossref]

22. Zhao Q, Huang ZJ, Yang S, Pan J, Smith B, Xu $B$. The utilization of antenatal care among ruralto-urban migrant women in Shanghai- a hospital-based cross-sectional study. BMC Public Health. $2012 ; 12 ; 1012$.

doi: 10.1186/1471-2458-12-1012 [Crossref]

23. Narayana Murthy MR, Siddalingappa $H$, Mishra B. Assessment of utilization of antenatal care services by mothers attending immunization sessions at a primary health centre in Mysore district, Karnataka, India. Int J Comm Med Pub Health. 2016;3(9)2561-2565.

doi: [Article] [Crossref] 